\title{
Oscillatory potentials in electroretinogram as an early marker of visual abnormalities in vitamin A deficiency
}

\author{
DAI KAKIUCHI ${ }^{1,2}$, TAISUKE UEHARA ${ }^{2}$, MOTOHIRO SHIOTANI $^{2}$, KYOKO NAKANO-ITO $^{2}$, \\ AKIYOSHI SUGANUMA ${ }^{2}$, TOYOHIKO AOKI ${ }^{2}$, KAZUO TSUKIDATE $^{2}$ and KOHEI SAWADA ${ }^{2}$ \\ ${ }^{1}$ Life Science Center of Tsukuba Advanced Research Alliance, Graduate School of Life and Environmental Sciences, \\ University of Tsukuba, Tsukuba, Ibaraki 305-8577; ${ }^{2}$ Eisai Product Creation Systems, \\ Eisai Co., Ltd., Tokodai, Tsukuba, Ibaraki 300-2635, Japan
}

Received December 9, 2013; Accepted September 12, 2014

DOI: $10.3892 / \mathrm{mmr} .2014 .2852$

\begin{abstract}
Vitamin A deficiency (VAD) caused by malnutrition and certain intestinal diseases induces visual impairments, including night blindness and photoreceptor cell dysfunction as indicated by reduced a- and b-waves in an electroretinogram (ERG). The effects of VAD on the inner retinal layer cells, including amacrine and ganglion cells, remain to be elucidated. The functions of these cells are reflected in oscillatory potentials (OPs), another component of the ERG. The present study investigated inner retinal layer cell function in VAD rats by analyzing OPs. In the present study, VAD was induced by feeding Brown Norway rats a vitamin A deficient diet for 10 weeks. A reduced body weight and peri-papillary opacification indicative of papilledema without histopathological alterations were observed, which are considered early symptoms of VAD. At this stage, the ERG revealed reduced OPs as well as a- and b-waves at various intensities of light stimulation. Further analysis indicated that the ratio of the alterations in OPs was more significant than those of a- and b-waves. After 5 weeks of recovery, these changes returned to control levels. These results suggest that OPs are the most sensitive and early marker of VAD-associated visual impairment in the ERG.
\end{abstract}

\section{Introduction}

Retinoids, derivatives of vitamin A (Vit A), have essential roles in visual phototransduction. In the initial step of visual phototransduction, conversion of 11-cis retinal to all-trans (AT) retinal occurs in photoreceptor cells subjected to light exposure. Vitamin A deficiency (VAD) reduces this activity

Correspondence to: Mr. Dai Kakiuchi, Eisai Product Creation Systems, Eisai Co., Ltd., 5-1-3, Tokodai, Tsukuba, Ibaraki 300-2635, Japan

E-mail: d-kakiuchi@hhc.eisai.co.jp

Key words: vitamin A deficiency, retinoid, oscillatory potentials, contrast sensitivity and subsequent downstream reactions in photoreceptor cells. As a result, patients with VAD exhibit visual abnormalities, including abnormal dark adaptation and night blindness, which may eventually progress to a severe visual impairment (1-3). Consistent with these clinical symptoms, electroretinogram (ERG) recordings in humans with VAD show decreases in amplitudes or loss of a- and b-waves, which reflect the function of photoreceptor and bipolar cells, respectively (1,3). A previous study reported that a reduced a-wave and a partial reduction of $b$-wave are induced by feeding albino rats a Vit A deficient diet for 8 weeks, with disintegration of the outer segments of photoreceptor cells (4). In contrast to the established effects of VAD on the a- and b-waves in ERG and histological alterations in photoreceptors, the effects of VAD on oscillatory potentials (OPs) remain to be elucidated. OPs, which are components of the ERG, are considered to be generated by the inner retinal layer cells, including amacrine and ganglion cells (5) and the reduction of OPs is known to be associated with reduced contrast sensitivity in diabetic patients (6). VAD has also been reported to reduce contrast sensitivity (7). Therefore, although, to the best of our knowledge, there are no studies indicating that VAD directly affects the formation of OPs or the function of inner retinal layer cells, it was hypothesized that OPs in ERG recordings may be affected during a state of VAD.

Another disease with known reduced contrast sensitivity is Parkinson's disease (PD). Patients with PD are also known to have reduced OPs $(8,9)$. In PD, the level of dopamine in the central nervous system (CNS) is decreased. Notably, retinoid is implicated in the regulation of gene expression of dopamine receptors (10-12). Dopamine receptors are present in amacrine cells and are known to be involved in visual signal transduction (7,13-15). This was supported by a previous study demonstrating that dopamine channel blockers can lead to a decline in OPs $(16,17)$. Retinoid receptors, including the retinoic acid receptor (RAR) and the retinoid $\mathrm{X}$ receptor (RXR), are present in amacrine cells $(18,19)$. This suggests that retinoids are associated with the dopamine pathway in visual transduction in the inner retinal layer cells. In order to assess this hypothesis, gene expression of dopamine receptors in the retina and spontaneous locomotor activity, an indicator of dopamine level in the CNS, were additionally measured 
to provide collateral evidence for the effects of VAD on the dopamine system.

The aim of the present study was to analyze the effects of VAD on the function of inner retinal layer cells, with a particular focus on OPs and possible involvement of the dopamine system. VAD rats were analyzed by ophthalmologic examination, including ERG recording and histology. The concentration of AT-retinol in the plasma was measured at specified time points to monitor the state of VAD. In addition, the present study evaluated the concentration of retinoids and gene expression of dopamine receptors in the retina. The reversibility of these parameters was also evaluated following a 5 week recovery period.

\section{Materials and methods}

Animals. In total, 36 male Brown Norway $(\mathrm{BN})$ rats were purchased at 21 days of age from Charles River Laboratories International, Inc. (Wilmington, MA, USA). All rats were subject to examination of the eyes via slit lamp and binocular indirect ophthalmoscope during the pretreatment period. Rats with no abnormal findings in either eye were selected and divided into VAD and control groups. A diet with or without Vit A was fed to the control and the VAD group, respectively. An AIN93G, Vit A (+) diet or an AIN93G-Vitamin A (-), Vit A (-) diet, were used. The two feed diets were obtained from Oriental Bioservice (Kyoto, Japan). Each animal was housed individually in a stainless steel cage within a clean air room operating a $12 \mathrm{~h}$ light/dark cycle. The room had controlled illumination $(<100 \mathrm{lux})$, temperature $\left(23-24^{\circ} \mathrm{C}\right)$ and humidity (53-71\%). The present study was performed in compliance with Laboratory Animal Policy at Eisai and was approved by the Laboratory Animal Care and Use Committee at Eisai Co., Ltd. (Tsukuba, Japan). All procedures were performed according to the ARVO Statement for the Use of Animals in Ophthalmic and Vision Research.

Study design. The first week of feeding the Vit A (-) diet was defined as week 1. To induce VAD in rats, the Vit A (-) diet was fed to 18 male BN rats for 10 weeks. Subsequently, a Vit A (+) diet was fed for 5 weeks (weeks 11-15) in order to examine recovery from VAD. The Vit A (+) diet was administered to 18 males in a control group for 15 weeks. In the VAD and control groups, 12 main study and six recovery rats were euthanized at weeks 10 and 15 , respectively, by exsanguination from the abdominal aorta under isoflurane anesthesia, for sampling of the eyes. Following euthanasia, the retina was collected. This stage was performed under a dim red light. All animals were weighed weekly. Blood was collected from the jugular vein of each of the 12 rats (euthanized at week 10) at weeks 6,8 and 10 to measure plasma concentration of AT-retinol. Prior to euthanasia, ophthalmologic examination, including ERG recording was performed on all surviving rats and measurement of spontaneous locomotor activity was conducted on each of six rats at weeks 10 and 15. At week 10, six and three right retinas were used for the measurement of retinoids and determination of the gene expression levels of dopamine receptors, respectively, in the VAD and control groups. The retinal retinoids were also measured using six right retinas in the two groups at week 15 . Six left eyes in the two groups were preserved in glutaraldehyde-formaldehyde and sectioned then coverslipped for microscopic examination at week 10 and 15 . The paraffin-embedded sections were stained with hematoxylin and eosin (H\&E).

\section{Retinoid determinations in plasma and the retina}

Reagents and standard derivatives. High performance liquid chromatography-grade solvents and reagents, acetonitrile, methanol, propanol and formic acid were purchased from Wako Pure Chemicals (Osaka, Japan). Ultra-pure water was prepared using a Millipore Milli-Q TOC system (Millipore, Billerica, MA, USA). The standard reagent of retinyl acetate was obtained from Kanto Chemical Co., Inc. (Tokyo, Japan). Internal standard solutions $(1 \mathrm{mg} / \mathrm{ml})$ were prepared in acetonitrile. To prepare working sample solutions for liquid chromatography-mass spectrometry (LC-MS), retinyl acetate stock solution was diluted to a final concentration of $5.0 \mu \mathrm{g} /$ $\mathrm{ml}$.

LC-MS analysis. An Applied Biosystems AB5000 mass spectrometer (Applied Biosystems, Foster City, CA, USA) with a Shimadzu prominence UFLC (Shimadzu, Kyoto, Japan) was used as the LC-atmospheric pressure chemical ionization (APCI)-MS system. The Waters Shield RP18 (2.0x150 mm; Waters Corporation, Milford, MA, USA) with Phenomenex security guard (C18, 2.0x4.0 mm; Phenomenex, Torrance, CA, USA) was selected as the stationary phase. The composition of mobile phase A was water/acetonitrile/formic acid (95:5:0.1) and the mobile phase B was propanol/acetonitrile (80:20). Linear gradients of mobile phase $\mathrm{B}$ were as follows: $0 \mathrm{~min}-1 \%, 0.5 \mathrm{~min}-1 \%$, $1.5 \mathrm{~min}-25 \%, 30 \mathrm{~min}-99 \%, 33 \mathrm{~min}-99 \%, 33.1 \mathrm{~min}-1 \%$ and $40 \mathrm{~min}$-stop. The flow rate of the mobile phase was $250 \mu \mathrm{l} / \mathrm{min}$ with $450 \mu \mathrm{l} / \mathrm{min}$ of post-column addition of methanol. An AB5000 mass spectrometer was used in APCI-multiple reaction monitoring (MRM) mode. Each condition of the MRM channel is listed in Table I.

The majority of the sample pretreatment processes were performed under a dim red light. For the plasma sample pretreatment, $50 \mu \mathrm{l}$ of plasma samples were transferred into shaded brown tubes $(1.5 \mathrm{ml})$ and mixed with $190 \mu \mathrm{l}$ of acetonitrile and $10 \mu \mathrm{l}$ of $5.0 \mu \mathrm{g} / \mathrm{ml}$ retinyl acetate in acetonitrile. Mixed solutions were centrifuged at $9,500 \mathrm{x}$ g for $20 \mathrm{~min}$. The supernatant was transferred to a plastic vial. For the tissue sample pretreatment, retinas were homogenized in $2.0 \mathrm{ml}$ of water/acetonitrile (25:75). Retinyl acetate $(100 \mu \mathrm{l}$ of $5.0 \mu \mathrm{g} / \mathrm{ml}$ ) in acetonitrile was added to $2.0 \mathrm{ml}$ of tissue homogenate. The sample $(250 \mu \mathrm{l})$ was transferred to shaded brown tubes $(1.5 \mathrm{ml})$. Mixed solutions were then centrifuged at $8,600 \mathrm{x} \mathrm{g}$ for $20 \mathrm{~min}$. Supernatants were then transferred to shaded plastic vials.

The quantity of plasma retinoid was calculated based on the quantity of retinyl acetate. In the present study, X-cis retinal included either 11-or 13-cis retinal due to technical difficulties in measuring the retinal separately.

Ophthalmologic examination. The ophthalmologic examinations with slit lamp or binocular indirect ophthalmoscope were performed on the eyes of all animals during the pretreatment period and at weeks 10 and 15 . Prior to observation, 
Table I. Condition of multiple reaction monitoring channels for liquid chromatography/mass spectrometric analysis.

\begin{tabular}{lcccccc}
\hline Retinoid & Q1 (Da) & Q2 (Da) & Dwell time (msec) & DP (volts) & CE (volts) & CXP (volts) \\
\hline Retinol (retinol esters) & 269.2 & 93.2 & 150 & 66 & 27 & 12 \\
Retinal & 285.1 & 161.3 & 150 & 71 & 15 & 18 \\
Retinoic acid & 301.2 & 123.3 & 150 & 66 & 25 & 18 \\
\hline
\end{tabular}

CE, collision energy; CXP, collision cell exit potential; DP, declustering potential.

the pupils were dilated by topical application of $0.5 \%$ tropicamide and $0.5 \%$ phenylephrine hydrochloride (Mydrin ${ }^{\circledR}-\mathrm{P}$, Santen Pharmaceutical Co., Ltd., Osaka, Japan). Images of the fundus were captured using a Kowa RC-2 fundus camera (Kowa, Tokyo, Japan).

ERG recording. Prior to ERG recording, rats from each group were adapted to the dark overnight and anesthetized with a combination of $40 \mathrm{mg} / \mathrm{kg}$ ketamine and $0.2 \mathrm{mg} / \mathrm{kg}$ xylazine by intramuscular injection. The pupils were dilated with $0.5 \%$ tropicamide and $0.5 \%$ phenylephrine $\mathrm{HCl}$. Rats were placed on an electric heater set at $25^{\circ} \mathrm{C}$ to prevent a decrease in body temperature until recording. Dark adaptation was maintained throughout the recording. ERG was recorded from the right eye of each animal using a contact lens type electrode (LS-W; Mayo, Inazawa, Japan). The recording electrode was placed in contact with the cornea, while a reference electrode was placed in the mouth. ERG responses were amplified and band-pass filtered between 0.5 and $200 \mathrm{~Hz}$, using a computer-assisted signal analysis system (MEB2200, Neuropack; Nihon Kohden, Tokyo, Japan). Light stimuli between 0.0003 and $30 \mathrm{~cd} \cdot \mathrm{s} / \mathrm{m}^{2}$ were provided by a flash stimulator (SLS-3100; Nihon Kohden). ERG response amplitudes and implicit time periods for a- and b-waves were determined based on the International Society for Clinical Electrophysiology of Vision (ISCEV) standard (20). OPs were also recorded from the right eye between 0.0003 and $3.0 \mathrm{~cd} \cdot \mathrm{s} / \mathrm{m}^{2}$ of light stimuli using similar methods to the ISCEV standard (20). A band-pass filter was set to $50-500 \mathrm{~Hz}$. The amplitudes and implicit time of OPs were determined as previously described (21). The amplitude of OPs was measured between the baseline and peak of each wavelet and the implicit time was measured between the stimulus onset and the peak of each wavelet. Each ERG response was recorded with intervals of $>30 \mathrm{sec}$ and the average of three flashes were calculated at each light stimuli level.

Locomotor activity. Spontaneous locomotor activity was measured using an automated motion analysis system (SCANET SV-20; Melquest, Toyama, Japan). Animals ( $\mathrm{n}=6$ for control and VAD rats) were assessed in the SCANET cage for $30 \mathrm{~min}$. Horizontal movements and the frequency of vertical movements caused by rearing were measured as previously described (22).

Quantitative polymerase chain reaction ( $q P C R)$ analysis. Gene expression was investigated using reverse transcription qPCR analysis (RT-qPCR). Total RNA was extracted from whole unilateral retina using an RNeasy mini kit (Qiagen, Hilden, Germany) at week 10 and converted to cDNA using SuperScript ${ }^{\circledR}$ III (Invitrogen Life Technologies, Carlsbad, CA, USA). Gene expression levels were quantified using an ABI7900HT Sequence Detection System (Invitrogen Life Technologies). The quantity of $\mathrm{mRNA}$ of dopamine receptor 1 (D1) and 2 (D2) was determined using specific probe sets (Assay ID: dopamine receptor D1A: Rn03062203_s1, dopamine receptor D2: Rn01418275_m1) of TaqMan Gene Expression Assays (Invitrogen Life Technologies). PCR was performed on $10 \mathrm{ng}$ of the obtained cDNA. PCR conditions were as follows: $50^{\circ} \mathrm{C}$ for $2 \mathrm{~min}, 95^{\circ} \mathrm{C}$ for $10 \mathrm{~min}, 40$ cycles of $95^{\circ} \mathrm{C}$ for $15 \mathrm{sec}$ and $60^{\circ} \mathrm{C}$ for $1 \mathrm{~min}$.

Statistical analysis. Student's t-test was used to compare the amplitude and implicit time of ERG components, the relative amplitude of b-waves and OPs to a-waves, the concentration of retinal retinoids and gene expression. Wilcoxon analysis was applied to locomotor activity data. The body weights and concentration of plasma retinoid were analyzed with repeated measures of analysis of variance. $\mathrm{P}<0.05$ was considered to indicate a statistically significant difference.

\section{Results}

Body weight. Body weights within the study period are shown in Fig. 1. A significantly lower body weight was observed from week 8 in VAD rats. During the recovery period, the body weight of VAD rats increased with similar growth rate compared with the control group. However, the difference in body weight between the control and VAD rats at week 10 $(44.5 \mathrm{~g})$ was maintained at week $15(55.3 \mathrm{~g})$.

Concentration of plasma AT-retinol. The concentration of plasma AT-retinol is shown in Fig. 2. The plasma AT-retinol levels in the control group were stable throughout the experimental period between 6 and 10 weeks with an average concentration of $\sim 800 \mathrm{ng} / \mathrm{ml}$ (minimal-maximal concentrations: $576-1012 \mathrm{ng} / \mathrm{ml}$ ). At week 6 , in the VAD group, the average concentration of plasma AT-retinol decreased to $393 \mathrm{ng} / \mathrm{ml}$ (min-max: 261-516 ng/ml). The average plasma concentrations of AT-retinol in VAD rats decreased further to $100 \mathrm{ng} / \mathrm{ml}$ (min-max: 57-161 ng/ml) and $36 \mathrm{ng} / \mathrm{ml}$ (min-max: $30-44 \mathrm{ng} / \mathrm{ml}$ ) at week 8 and 10 , respectively.

Retinal retinoids. The levels of all measurable retinal retinoids were significantly lower in VAD rats compared with the control rats at week 10 (Fig. 3A). AT-retinol, 


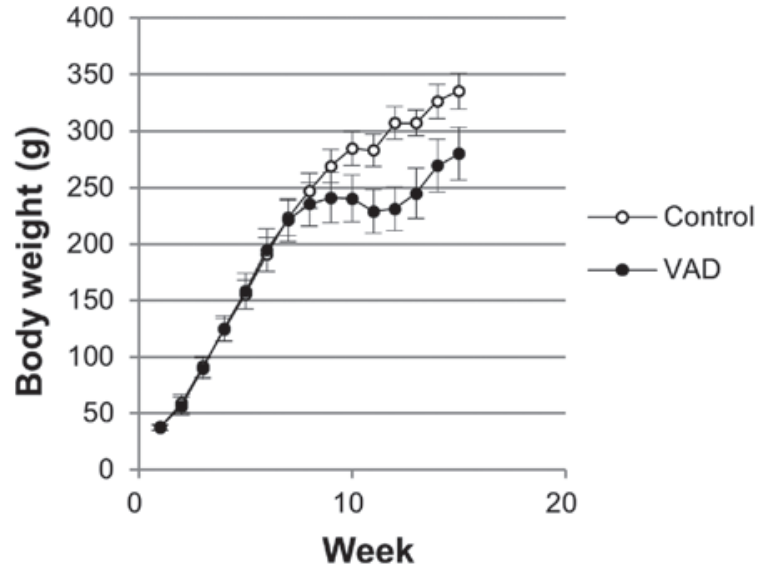

Figure 1. Comparison of body weight between control and VAD rats. Plots of body weight for control and VAD rats. The mean values of 18 rats are shown Bars represent standard deviation (analysis of variance, $\mathrm{F}(61,368)=15.585$ $\mathrm{P}<0.001)$. VAD, vitamin A deficiency.

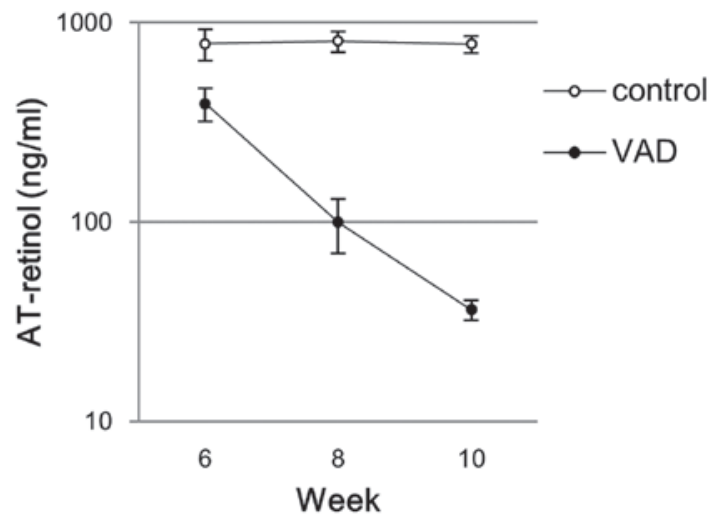

Figure 2. Comparison of plasma AT retinol between control and VAD rats. Concentration of plasma AT retinol in control and VAD rats at weeks 6, 8 and 10. The mean values of 12 rats are shown. Bars represent standard deviation. (analysis of variance, $\mathrm{F}(36,36)=0.410 ; \mathrm{P}<0.001)$. VAD, vitamin A deficiency; AT, all-trans.

AT-retinal and AT-retinoic acid in the VAD group decreased $(1.4-->0.8 \mathrm{ng} / \mathrm{ml}, 129.0-->83.8 \mathrm{ng} / \mathrm{ml}$ and 9.7-->4.9 $\mathrm{ng} / \mathrm{ml}$, respectively). 9-cis retinol and retinal decreased by 85 and $54 \%$, respectively. X-cis retinal containing 11- and 13-cis retinal decreased by $46 \%$. These alterations almost returned to control levels by week 15 (Fig. 3B).

ERG recording. Typical ERG wave forms, which were recorded at 0.0003-30 cd.s/ $/ \mathrm{m}^{2}$ at week 10, are shown in Fig. 4. The reduction of OPs in the VAD rats was clearly evident from these traces. The association between light intensity and amplitude or implicit time of a- and b-waves is shown in Fig. 5A and B, respectively. The amplitude of the b-wave was significantly decreased to $\sim 50 \%$ of the control value at a light intensity $>0.003 \mathrm{~cd} \cdot \mathrm{s} / \mathrm{m}^{2}$ at week 10 . The amplitude of the a-wave was also significantly decreased at light intensities $>0.3 \mathrm{~cd} \cdot \mathrm{s} / \mathrm{m}^{2}$. There were significant reductions in the implicit time of $b$-waves in the VAD rats compared with the control at light intensities $>3.0 \mathrm{~cd} \cdot \mathrm{s} / \mathrm{m}^{2}$. Partial prolongations of the implicit time of the a-wave were observed at light intensities
A

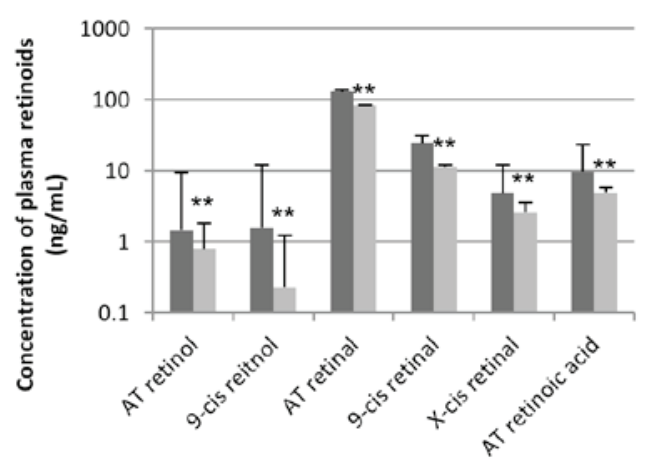

B

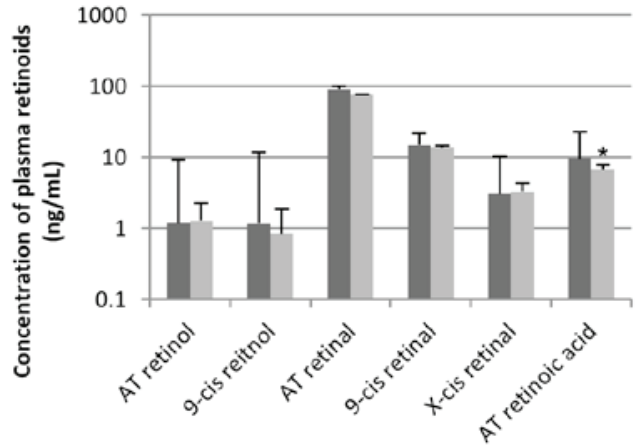

Figure 3. Comparison of retinoids in the retinas of the control and vitamin A deficient (VAD) rats. Black bars represent the mean values of the control group and gray bars represent the mean values of the VAD group. (A) Mean value of measurable retinoids in the retinas of VAD and control rats $(n=6)$ at week 10. (B) Mean value of measurable retinoids in the retinas of the VAD and control rats $(n=6)$ at week 15 . Bars represent standard deviation. ${ }^{*} \mathrm{P}<0.05$, ${ }^{* *} \mathrm{P}<0.01$ compared with the control group. AT, all trans.
A

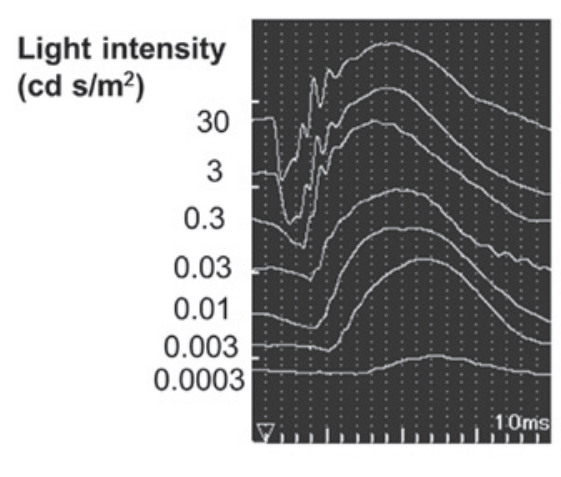

C

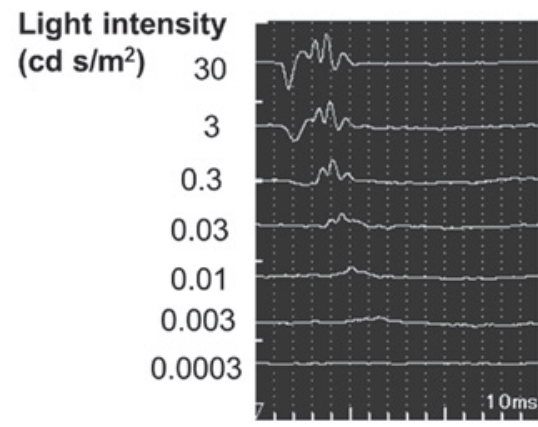

B

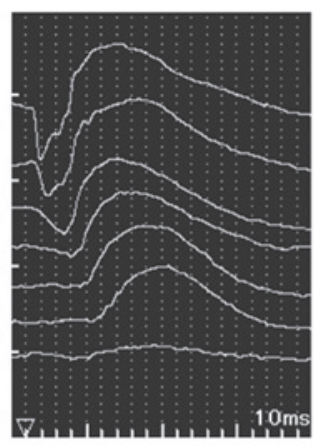

D

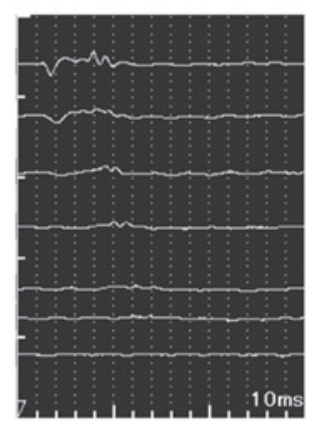

Figure 4. Typical ERG wave forms of control and VAD rats at week 10. Dark adapted ERG wave forms produced by $0.0003-30 \mathrm{~cd} \cdot \mathrm{s} / \mathrm{m}^{2}$ of light stimuli in (A) control and (B) VAD rats are shown. Wave forms of OPs produced by $0.0003-3.0 \mathrm{~cd} \cdot \mathrm{s} / \mathrm{m}^{2}$ of light stimuli are shown in (C) control and (D) VAD rats. ERG, electroretinogram; VAD, vitamin A deficiency. 
A

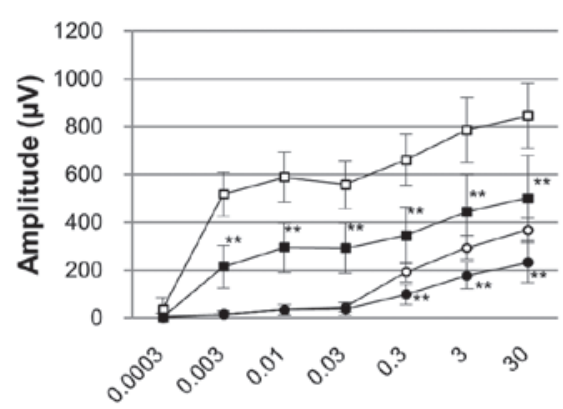

Light intensity $\left(\mathbf{c d} \cdot \mathbf{s} / \mathrm{m}^{2}\right)$

C

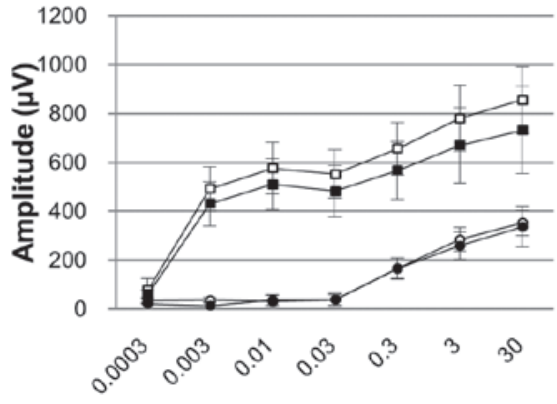

Light intensity $\left(\mathbf{c d} \cdot \mathbf{s} / \mathrm{m}^{2}\right)$
B

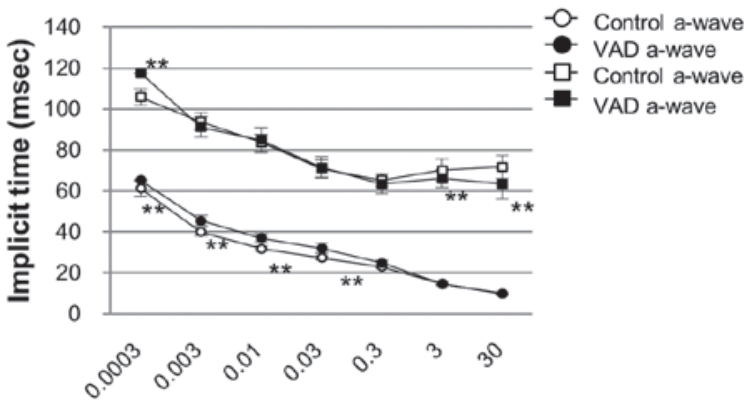

Light intensity $\left(\mathrm{cd} \cdot \mathrm{s} / \mathrm{m}^{2}\right)$

D

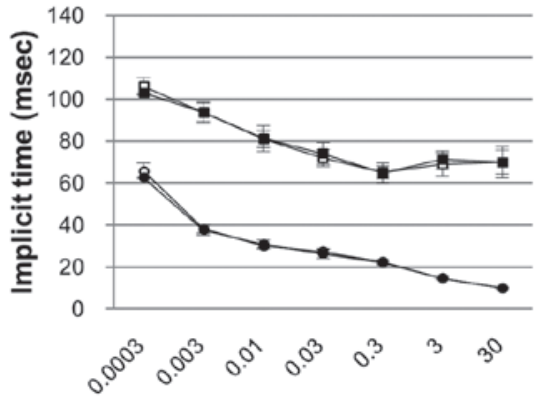

Light intensity $\left(\mathbf{c d} \cdot \mathbf{s} / \mathrm{m}^{2}\right)$

Figure 5. Correlation of the amplitude and the implicit time of ERG components to light intensity at weeks 10 and 15 . The mean responses of six to eight rats to seven flashes of 0.0003-30 cd.s $/ \mathrm{m}^{2}$ are shown. Bars represent standard deviation. (A and C) Amplitude and (B and D) implicit time of a- and b-waves at (A and B) weeks 10 and (C and D) 15. ERG, electroretinogram; VAD, vitamin A deficiency.

$<0.03 \mathrm{~cd} \cdot \mathrm{s} / \mathrm{m}^{2}$ with statistical significance. However, no significant differences were identified in the implicit time of a-wave between VAD and control rats at light intensity $>3.0 \mathrm{~cd} \cdot \mathrm{s} / \mathrm{m}^{2}$. No differences were observed in the amplitude and implicit time between VAD and control rats at week 15 (Fig. 5C and D).

OPs of VAD rats were smaller than those of control rats at week 10 (Fig. 4C and D). A summary of amplitudes and implicit time periods of OPs recorded at $0.03-3.0 \mathrm{~cd} \cdot \mathrm{s} / \mathrm{m}^{2}$ is shown in Tables II and III. OPs recorded at $<0.01 \mathrm{~cd} \cdot \mathrm{s} / \mathrm{m}^{2}$ were not listed in these tables as they could not be detected in the majority of control animals. The mean amplitudes of OP1, 2 and 3 and summed OPs $(\Sigma \mathrm{OPs}=\mathrm{OP} 1+\mathrm{OP} 2+\mathrm{OP} 3+\mathrm{OP} 4)$ in VAD rats were significantly decreased to $35-71 \%$ of control rats at week 10. In several VAD rats, loss of all OP wavelets was observed at $<0.3 \mathrm{~cd} \cdot \mathrm{s} / \mathrm{m}^{2}$. At 3.0 and $30 \mathrm{~cd} \cdot \mathrm{s} / \mathrm{m}^{2}$, loss of OP peaks was noted. The mean implicit time of OP1 and 2 were slightly prolonged at multi-intensity at week 10 . These changes returned to control levels at week 15. Relative amplitudes of b-wave (b/a) and $\Sigma \mathrm{OPs}$ ( $\Sigma \mathrm{OPs} / \mathrm{a})$ to a-wave at $3.0 \mathrm{~cd} \cdot \mathrm{s} / \mathrm{m}^{2}$ are shown in Fig. 6. While the b/a of VAD rats was comparable to the control value, $\Sigma \mathrm{OPs} / \mathrm{a}$ was significantly decreased at week 10 (Fig. 6A) and returned to the level of the control following the recovery period (Fig. 6B). The data suggest that VAD significantly affected OPs more so than a- and b-waves.

Ophthalmologic examination. Binocular indirect ophthalmoscope observation of the fundus revealed peri-papillary opacification and was identified in all VAD rats at week 10 (Table IV and Fig. 7). At week 15, the region of opacification became smaller, however, did not disappear. There were no other VAD-associated changes in anterior and posterior chambers and the optic media during the experimental period.

Histopathological examination. Six left eyes of control and VAD rats were histopathologically observed at weeks 10 and 15 using H\&E staining. There were no notable findings in the retina, including photoreceptor cells, inner retinal layer cells and papilla.

Locomotor activity. In VAD rats, horizontal movements tended to decrease and the frequency of rearing was significantly lower at week 10 compared with the control rats (Fig. 8, horizontal movement at week $10, \mathrm{P}=0.31$; rearing at week 10 , $\mathrm{P}=0.04)$. At week 15 , no apparent differences between VAD and control rats were observed under these parameters (Fig. 8, horizontal movement at week $15, \mathrm{P}=0.438$; rearing at week 15 , $\mathrm{P}=0.485$ ).

Gene expression of DR. The mRNA of D1 and D2 in the retina was investigated with RT-qPCR at week 10 (Fig. 9). The expression levels of D1 and D2 in VAD rats were partially decreased compared with the control rats, however, no statistical significance was identified (D1, P=0.13; D2, P=0.16).

\section{Discussion}

It has previously been demonstrated that VAD causes dysfunction of photoreceptor cells (23). VAD induces a decrease in 11-cis retinal, which is necessary for the synthesis of rhodopsin. This leads to insufficient phototransduction from light to electrical signals and a decline in a-waves in an ERG. 
Table II. Summary of the amplitude and implicit time of each OP wavelet and summed OPs at Week 10.

\begin{tabular}{|c|c|c|c|c|c|c|c|c|c|}
\hline \multirow{2}{*}{$\begin{array}{l}\text { Light } \\
\text { intensity }\end{array}$} & \multicolumn{5}{|c|}{ Amplitude $(\mu \mathrm{V})$} & \multicolumn{4}{|c|}{ Implicit time (msec) } \\
\hline & OP1 & OP2 & OP3 & OP4 & $\Sigma \mathrm{OP}$ & OP1 & OP2 & OP3 & OP4 \\
\hline \multicolumn{10}{|c|}{$0.03 \mathrm{~cd} \cdot \mathrm{s} / \mathrm{m}^{2}$} \\
\hline \multicolumn{10}{|l|}{ Control } \\
\hline AV & 34.6 & 83.8 & 45.8 & 6.8 & 170.9 & 30.1 & 35.6 & 42.0 & 52.4 \\
\hline SD & 5.2 & 12.4 & 18.7 & 10.9 & 34.9 & 1.2 & 1.0 & 1.2 & 3.6 \\
\hline \multicolumn{10}{|l|}{ VAD } \\
\hline AV & $15.3^{b}$ & $37.8^{b}$ & $21.6^{b}$ & 2.6 & $77.2^{\mathrm{b}}$ & $34.8^{b}$ & $40.6^{b}$ & $47.2^{b}$ & 55.7 \\
\hline SD & 12.9 & 29.7 & 16.7 & 5.3 & 59.4 & 2.6 & 2.7 & 3.2 & 5.1 \\
\hline \multicolumn{10}{|c|}{$0.3 \mathrm{~cd} \cdot \mathrm{s} / \mathrm{m}^{2}$} \\
\hline \multicolumn{10}{|l|}{ Control } \\
\hline AV & 75.8 & 134.8 & 44.8 & 3.4 & 258.8 & 26.1 & 31.6 & 39.1 & 50.0 \\
\hline SD & 17.8 & 30.6 & 12.7 & 3.4 & 58.8 & 2.3 & 2.2 & 2.2 & 3.3 \\
\hline \multicolumn{10}{|l|}{ VAD } \\
\hline AV & $32.6^{b}$ & $68.6^{* *}$ & $31.8^{\mathrm{a}}$ & 5.5 & $130.9^{b}$ & $28.9^{b}$ & $34.6^{b}$ & 41.0 & 50.0 \\
\hline SD & 19.6 & 26.4 & 21.3 & 8.9 & 64.0 & 2.8 & 2.6 & 3.4 & 5.3 \\
\hline \multicolumn{10}{|c|}{$3.0 \mathrm{~cd} \cdot \mathrm{s} / \mathrm{m}^{2}$} \\
\hline \multicolumn{10}{|l|}{ Control } \\
\hline AV & 120.1 & 161.6 & 50.4 & 3.2 & 335.4 & 24.3 & 30.3 & 38.3 & 48.1 \\
\hline SD & 27.2 & 38.3 & 13.9 & 2.6 & 78.8 & 2.2 & 2.4 & 2.5 & 1.7 \\
\hline \multicolumn{10}{|l|}{ VAD } \\
\hline AV & $45.4^{b}$ & $77.3^{\mathrm{b}}$ & $33.1^{\mathrm{b}}$ & 5.1 & $161.0^{b}$ & $26.9^{\mathrm{a}}$ & $32.6^{\mathrm{a}}$ & 39.3 & 47.1 \\
\hline SD & 25.3 & 34.9 & 19.6 & 6.7 & 73.9 & 3.3 & 2.9 & 4.1 & 4.2 \\
\hline \multicolumn{10}{|c|}{$30.0 \mathrm{~cd} \cdot \mathrm{s} / \mathrm{m}^{2}$} \\
\hline \multicolumn{10}{|l|}{ Control } \\
\hline AV & 129.5 & 181.5 & 54.5 & 5.8 & 371.4 & 22.4 & 28.7 & 37.1 & 48.0 \\
\hline SD & 28.3 & 45.8 & 15.1 & 3.4 & 87.6 & 2.7 & 2.6 & 2.6 & 2.8 \\
\hline \multicolumn{10}{|l|}{ VAD } \\
\hline AV & $45.4^{b}$ & $84.3^{b}$ & $36.1^{b}$ & 4.6 & $170.4^{b}$ & $24.6^{\mathrm{a}}$ & $30.5^{a}$ & 37.5 & 45.7 \\
\hline SD & 23.2 & 35.9 & 20.9 & 5.6 & 73.8 & 2.5 & 2.4 & 3.0 & 3.9 \\
\hline
\end{tabular}

$\mathrm{AV}$, average; $\mathrm{SD}$, standard deviation. Bold figures mean the values have statistical significance. The amplitude and implicit time of each OP wavelet and summed OPs in vitamin A deficient rats were compared with those of control rats. The mean and standard deviation of each wavelet and $\Sigma$ OPs are shown at week $10 .{ }^{\mathrm{a}} \mathrm{P}<0.05$ and ${ }^{\mathrm{b}} \mathrm{P}<0.01$, versus control. OP, oscillatory potential.

The present results were consistent with these changes. In VAD animals, occurrence of papilledema is also reported as a result of increased cerebrospinal fluid pressure (24). In the present study, peri-papillary opacification, one of the properties of papilledema (25), was noted in all VAD rats. These results and the significant reduction of plasma AT-retinol confirm that VAD was induced in rats administered a Vit A (-) diet for 10 weeks in the present study. By contrast, no histopathological alterations were observed in the retina of VAD rats at week 10, nor was there body weight loss, xerophthalmia, xerosis or keratomalacia indicative of an advanced VAD state (4). These results indicate that only functional impairments of the retina were induced by feeding a Vit A (-) diet to $\mathrm{BN}$ rats for 10 weeks and the VAD rats in the present study were considered to be at an early stage of VAD disease.
In outer retinal layer cells, the electrical stimulus is transmitted to and activates bipolar cells through glutamate released from photoreceptor cells. The activation of bipolar cells is reflected in the b-wave in an ERG (5). Accordingly, it is expected that the magnitude of the b-wave depends on that of the a-wave. No difference in the b/a ratio between control and VAD rats was identified in the present study suggesting that the there was no interference in the signal transmission from photoreceptor cells to bipolar cells by VAD. The signal from bipolar cells subsequently activates the inner retinal layer cells, including amacrine cells. The reduction of a-waves may lead to the decreased input to bipolar cells and subsequently reduced signal transduction from bipolar cells to amacrine cells, which generate OPs. Therefore, there may be a corresponding decrease in OPs following the reduction of the a-wave. In the present study, 
Table III. Summary of the amplitude and implicit time of each OP wavelet and summed OPs at week 15.

\begin{tabular}{|c|c|c|c|c|c|c|c|c|c|}
\hline \multirow{2}{*}{$\begin{array}{l}\text { Light } \\
\text { intensity }\end{array}$} & \multicolumn{5}{|c|}{ Amplitude $(\mu \mathrm{V})$} & \multicolumn{4}{|c|}{ Implicit time (msec) } \\
\hline & OP1 & $\mathrm{OP} 2$ & OP3 & OP4 & $\Sigma \mathrm{OP}$ & OP1 & OP2 & OP3 & OP4 \\
\hline \multicolumn{10}{|c|}{$0.03 \mathrm{~cd} \cdot \mathrm{s} / \mathrm{m}^{2}$} \\
\hline \multicolumn{10}{|c|}{ Control } \\
\hline $\mathrm{AV}$ & 36.2 & 67.2 & 38.2 & 3.3 & 144.8 & 29.9 & 35.2 & 41.5 & 51.1 \\
\hline SD & 20.0 & 40.8 & 21.7 & 5.3 & 80.2 & 0.9 & 1.2 & 1.1 & 2.1 \\
\hline \multicolumn{10}{|l|}{ VAD } \\
\hline AV & 30.3 & 67.7 & 41.7 & 4.0 & 143.7 & 28.9 & 34.8 & 41.3 & 51.0 \\
\hline SD & 17.5 & 37.4 & 25.7 & 5.5 & 80.0 & 0.7 & 0.5 & 0.7 & 2.1 \\
\hline \multicolumn{10}{|c|}{$0.3 \mathrm{~cd} \cdot \mathrm{s} / \mathrm{m}^{2}$} \\
\hline \multicolumn{10}{|c|}{ Control } \\
\hline $\mathrm{AV}$ & 76.8 & 139.7 & 45.3 & 10.3 & 272.2 & 25.0 & 30.5 & 38.3 & 47.6 \\
\hline SD & 16.7 & 32.0 & 14.5 & 6.9 & 59.5 & 0.8 & 0.7 & 1.8 & 1.8 \\
\hline \multicolumn{10}{|l|}{ VAD } \\
\hline AV & 73.8 & 139.0 & 40.5 & 6.0 & 259.3 & 25.0 & 30.3 & 38.4 & 49.4 \\
\hline SD & 16.9 & 27.6 & 11.1 & 3.6 & 55.1 & 0.5 & 0.4 & 0.8 & 0.7 \\
\hline \multicolumn{10}{|c|}{$3.0 \mathrm{~cd} \cdot \mathrm{s} / \mathrm{m}^{2}$} \\
\hline \multicolumn{10}{|l|}{ Control } \\
\hline $\mathrm{AV}$ & 126.8 & 174.8 & 54.3 & 8.5 & 364.5 & 23.4 & 29.1 & 37.5 & 46.6 \\
\hline $\mathrm{SD}$ & 19.8 & 40.3 & 13.8 & 4.8 & 72.5 & 0.6 & 0.6 & 1.6 & 1.7 \\
\hline \multicolumn{10}{|l|}{ VAD } \\
\hline AV & 117.8 & 165.2 & 45.3 & 2.5 & 330.8 & 23.0 & 28.9 & 37.5 & 47.9 \\
\hline $\mathrm{SD}$ & 24.7 & 26.9 & 14.6 & 3.6 & 66.4 & 0.4 & 0.7 & 0.7 & 1.3 \\
\hline \multicolumn{10}{|c|}{$30.0 \mathrm{~cd} \cdot \mathrm{s} / \mathrm{m}^{2}$} \\
\hline \multicolumn{10}{|c|}{ Control } \\
\hline $\mathrm{AV}$ & 137.2 & 194.5 & 54.7 & 6.3 & 392.7 & 21.5 & 27.5 & 36.1 & 46.5 \\
\hline SD & 24.2 & 43.8 & 15.0 & 5.5 & 79.8 & 0.5 & 0.6 & 0.8 & 1.4 \\
\hline \multicolumn{10}{|l|}{ VAD } \\
\hline AV & 124.7 & 181.5 & 45.8 & 3.2 & 355.2 & 21.1 & 27.2 & 36.0 & 46.6 \\
\hline SD & 26.4 & 34.4 & 12.8 & 1.5 & 70.5 & 0.3 & 0.5 & 0.5 & 1.0 \\
\hline
\end{tabular}

$\mathrm{AV}$, average, SD, standard deviation. The amplitude and implicit time of each OP wavelet and summed OPs in vitamin A deficient rats were compared with those of control rats. The mean and standard deviation of each wavelet and $\Sigma$ OPs are shown at weeks 15 . OP, oscillatory potential.

there was decreased amplitude of the a-wave with strong light intensities in VAD rats with decreases in OPs at week 10. However, analysis demonstrated a significant reduction of $\Sigma$ OPs/a in VAD rats at week 10 , despite having no changes in $\mathrm{b} / \mathrm{a}$, indicating a greater magnitude of reduction in OPs than the reduction secondary to a-wave reduction alone. OPs are considered to be generated by the activation of amacrine cells (3), which release several neurotransmitters, including dopamine, $\gamma$-aminobutyric acid (GABA) and glycine in order to stimulate other amacrine or ganglion cells $(16,26)$; inhibitors of these neurotransmitters are known to decrease OPs (16). The significant reduction of $\Sigma$ OPs/a in VAD rats possibly indicates that VAD affects not only the functions of photoreceptor cells but also signal transduction of inner retinal layer cells via these neurotransmitters.
Table IV. Summary of peri-papillary opacification identified at weeks 10 and 15.

Control group Vitamin VAD group

\begin{tabular}{lcc}
\hline Week 10 & & \\
Right eye & $0 / 18$ & $18 / 18$ \\
Left eye & $0 / 18$ & $18 / 18$ \\
Week 15 & & \\
Right eye & $0 / 6$ & $6 / 6$ \\
Left eye & $0 / 6$ & $6 / 6$ \\
\hline
\end{tabular}

Peri-papillary opacification identified at Weeks 10 and 15 are summarized in this table. VAD, vitamin A deficiency. 

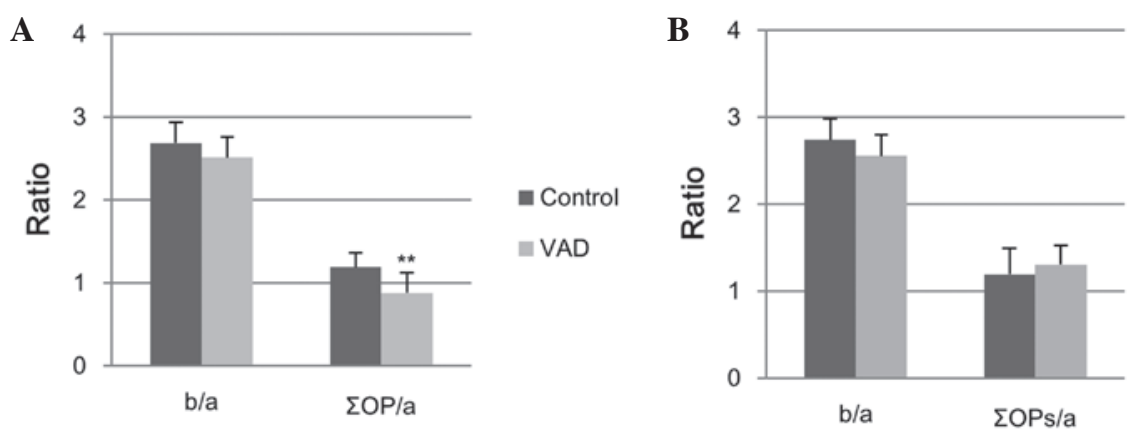

Figure 6. Effect of VAD on the relative amplitude of b-wave and $\Sigma \mathrm{OPs}$ to that of a-wave. The mean values of b/a and $\Sigma \mathrm{OPs} / \mathrm{a}$ at (A) week 10 and (B) 15 are shown. Bars represent standard deviation. ${ }^{* *} \mathrm{P}<0.01$, compared with the control group. VAD, vitamin A deficiency.

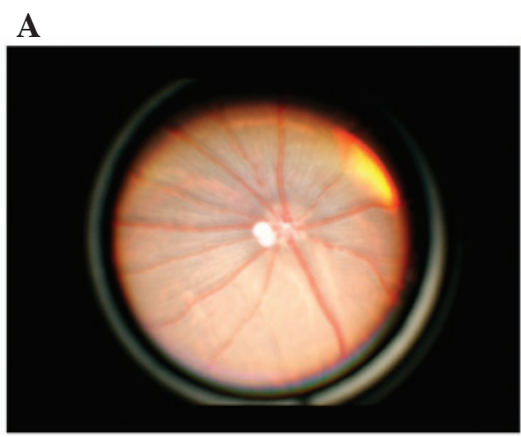

B

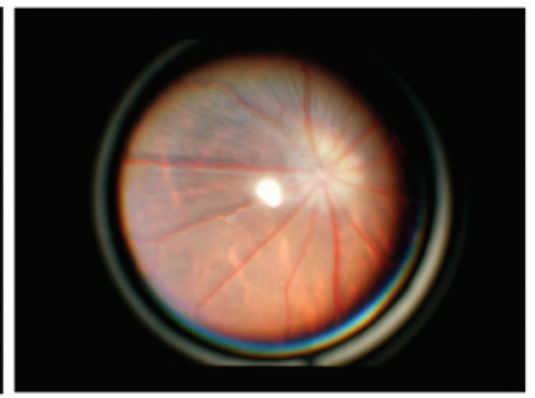

Figure 7. Fundus imaging at week 10. (A and B) Images of the fundus in control and vitamin A deficient rats, respectively.

A
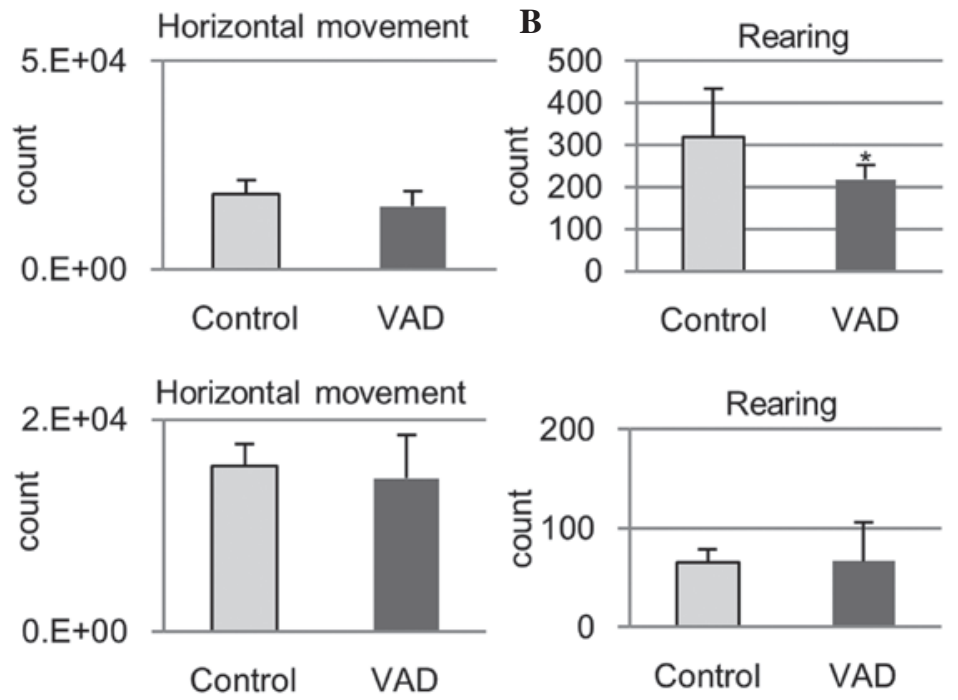

Figure 8. Comparison of locomotor activities between control and VAD rats. The mean values reveal (A) total frequency of horizontal movements and the (B) frequency of rearing with the standard deviation at weeks (A) 10 and (B) $15 .{ }^{*} \mathrm{P}<0.05$, compared with the vehicle control. VAD, vitamin A deficiency.
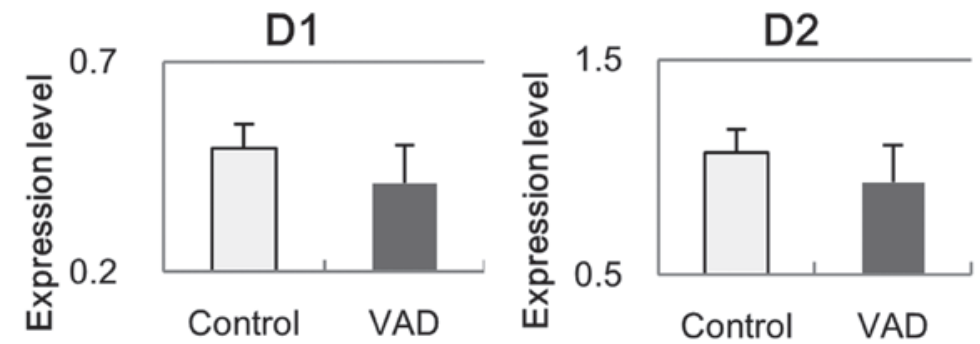

Figure 9. Expression levels of D1 and D2 receptors in control and VAD rats at week 10. The mean values of mRNA levels of D1 and D2 receptors are shown with standard deviation $(\mathrm{n}=3)$. VAD, vitamin A deficiency; D1, dopamine 1; D2, dopamine 2. 
In the CNS, 9-cis retinoic acid, a retinoid, is known to regulate gene expression of dopamine receptors via nuclear receptors, RAR and RXR (10-12,27). The greater decrease in 9-cis retinoic acid was suggested by the notable reduction of endogenous precursors, 9-cis retinol and retinal (28). The retinoid receptor mutant mouse shows decreases in locomotor activity, which is an indication of dopamine levels in the CNS (29). The significant reduction in rearing count in the present study indicates that a similar decrease in dopamine receptors by retinoids is present in VAD rats. A previous study have reported that dopamine acts as an important chemical messenger within amacrine cells or between amacrine cells and ganglion cells in the retina activating the dopamine pathway via D1 and D2 dopamine receptors (8). Based on the decreases in 9-cis retinol and retinal in the retina and rearing count, it was hypothesized that VAD induced downregulation of dopamine receptors in the inner retinal layer cells with a decrease in OPs. Although no statistically significant difference was identified in the mRNA levels of D1 and D2 in the retina between VAD and control rats, there was a reduction in these levels. This may indicate that additional factors contribute to the decline of OPs in VAD rats. A previous study indicated that retinoic acid is required for activation of glutamic acid decarboxylase that converts glutamate to GABA (30). The decline of OPs in VAD rats may be affected by a variety of factors associated with abnormalities in the levels of neurotransmitters and decreased photoreceptor output.

The present study demonstrated for the first time, to the best of our knowledge, that VAD affects the generation of OPs. The decreased OPs possibly reflect reduced contrast sensitivity in patients with VAD and may also be used for prediction of, or for early detection of other conditions with reduced contrast sensitivity. The model used in the present study may also provide an animal model for research associated with abnormalities in OPs.

\section{Acknowledgements}

The authors would like to thank Dr A. Fukamizu of Tsukuba University for invaluable advice.

\section{References}

1. Dowling JE and Wald G: Vitamin A deficiency and night blindness. Proc Natl Acad Sci USA 44: 648-661, 1958.

2. McLaren DS: Vitamin A deficiency disorders. J Indian Med Assoc 97: 320-323, 1999.

3. Byron L Lam (ed): Nutritional, Toxic, and Pharmacological Effects. In: Electrophysiology of Vision: Clinical Testing and Applications. Vol 1. 1st Edition. Taylor \& Francis Group, Florida, pp 407-435, 2005.

4. Dowling JE and Wald G: Nutritional night blindness. Ann NY Acad Sci 74: 256-265, 1959

5. Byron L Lam (ed): Full-Field Electroretinogram. In: Electrophysiology of Vision. Clinical Testing and Applications. Vol 1. 1st Edition. Taylor \& Francis Group, Florida, pp 1-47, 2005

6. Kawasaki K, Yonemura K, Yokogawa Y, Saito N and Kawakita S: Correlation between ERG oscillatory potential and psychophysical contrast sensitivity in diabetes. Doc Ophthalmol 64 209-215, 1986.

7. Leguire LE, Pappa KS, Kachmer ML, Rogers GL and Bremer DL: Loss of contrast sensitivity in cystic fibrosis. Am J Ophthalmol 111: 427-429, 1991.
8. Witkovsky P: Dopamine and retinal function. Doc Ophthalmol 108: 17-40, 2004.

9. Jaffe MJ, Bruno G, Campbell G, Lavine RA, Karson CN and Weinberger DR: Ganzfeld electroretinographic findings in parkinsonism: untreated patients and the effect of levodopa intravenous infusion. J Neurol Neurosurg Psychiatry 50: 847-852, 1987.

10. Samad TA, Krezel W, Chambon P and Borrelli E: Regulation of dopaminergic pathways by retinoids: activation of the D2 receptor promoter by members of the retinoic acid receptor-retinoid x receptor family. Proc Natl Acad Sci USA 94: 14349-14354, 1997.

11. Wang HF and Liu FC: Regulation of multiple dopamine signal transduction molecules by retinoids in the developing striatum. Neuroscience 134: 97-105, 2005.

12. Bremner JD and McCaffery P: The neurobiology of retinoic acid in affective disorders. Prog Neuropsychopharmacol Biol Psychiatry 32: 315-331, 2008.

13. Veruki ML and Wässle H: Immunohistochemical localization of dopamine D1 receptors in rat retina. Eur J Neurosci 8: 2286-2297, 1996.

14. Veruki ML: Dopaminergic neurons in the rat retina express dopamine D2/3 receptors. Eur J Neurosci 9: 1096-1100, 1997.

15. Nguyen-Legros J, Versaux-Botteri $C$ and Vernier P: Dopamine receptor localization in the mammalian retina. Mol Neurobiol 19: 181-204, 1999.

16. Wachtmeister L: Oscillatory potentials in the retina: what do they reveal. Prog Retin Eye Res 17: 485-521, 1998.

17. Kirk N Gelatt (ed): Ophthalmic Examination and Diagnostics. In: Veterinary Ophthalmology. Vol 2. 4th edition. Oxfordshire Blackwell Publishing, Oxford, UK, pp 484-535, 2007.

18. Fischer AJ, Wallman J, Mertz JR and Stell WK: Localization of retinoid binding proteins, retinoid receptors, and retinaldehyde dehydrogenase in the chick eye. J Neurocytol 28: 597-609, 1999.

19. Mori M, Ghyselinck NB, Chambon P and Mark M: Systematic immunolocalization of retinoid receptors in developing and adult mouse eyes. Invest Ophthalmol Vis Sci 42: 1312-1318, 2001.

20. Marmor MF, Fulton AB, Holder GE, Miyake Y, Brigell M and Bach M: International Society for Clinical Electrophysiology of Vision. ISCEV standard for full-field clinical electroretinography (2008 update). Doc Ophthalmol 118: 69-77, 2009.

21. Yamashita H, Yamada-Nakayama C, Sugihara K, et al: Functional and morphological effects of $\beta$-estradiol in eyes with N-methyl-D-Aspartate-induced retinal neurotoxicity in rats. Exp Eye Res 93: 75-81, 2011.

22. Matsumoto A, Okada Y, Nakamichi M, et al: Disease progression of human SOD1 (G93A) transgenic ALS model rats. J Neurosci Res 83: 119-133, 2006.

23. Katz ML, Chen DM, Stientjes HJ and Stark WS: Photoreceptor recovery in retinoid-deprived rats after vitamin A replenishment. Exp Eye Res 56: 671-682, 1993.

24. Kirk N Gelatt (ed): Ocular Manifestations of Systemic Diseases. In: Veterinary Ophthalmology. Vol 2. 4th edition. Oxfordshire Blackwell Publishing, Oxford, UK, pp 1617-1643, 2007.

25. Scott CJ, Kardon RH, Lee AG, Frisén L and Wall M: Diagnosis and grading of papilledema in patients with raised intracranial pressure using optical coherence tomography vs clinical expert assessment using a clinical staging scale. Arch Ophthalmol 128: 705-711, 2010.

26. Wachtmeister L: Further studies of the chemical sensitivity of the oscillatory potentials of the electroretinogram (ERG) I. GABA- and glycine antagonists. Acta Ophthalmol (Copenh) 58: 712-725, 1980

27. Bondioni S, Angioni AR, Corbetta S, et al: Effect of 9-cis retinoic acid on dopamine D2 receptor expression in pituitary adenoma cells. Exp Biol Med (Maywood) 233: 439-446, 2008.

28. Romert A, Tuvendal P, Simon A, Dencker L and Eriksson U: The identification of a 9-cis retinol dehydrogenase in the mouse embryo reveals a pathway for synthesis of 9 -cis retinoic acid. Proc Natl Acad Sci USA 95: 4404-4409, 1998.

29. Krezel W, Ghyselinck N, Samad TA, et al: Impaired locomotion and dopamine signaling in retinoid receptor mutant mice. Science 279: 863-867, 1998.

30. Bain G, Ramkumar TP, Cheng JM and Gottlieb DI: Expression of the genes coding for glutamic acid decarboxylase in pluripotent cell lines. Brain Res Mol Brain Res 17: 23-30, 1993. 